\title{
JUN 221999
}

Station 19

2. To: (Receiving Organization)

ist $x$ ibution

F. Proj/Prog/Dept/Div.:

Fuel Retriewal SubProject $A-7$

3. From: (Originating Organization)

Fuel Retrieval Subproject

6. Design Authority/Design Agent/Cog. Engr.:

E. J.' Shen

3. Originator Remarks:

For Release

1. Receiver Remarks:

11A. Design Baseline Document? $\mathrm{Y}$ Yes

O No

4. Related EDT No.:

$\mathrm{N} / \mathrm{A}$

7. Puichase Order No.:

$\mathrm{N} / \mathrm{A}$

9. Equip./Component No.:

$\mathrm{N} / \mathrm{A}$

10. System/BIdg/Facility:

12. Major Assm. Dwg. No.:

$\mathrm{N} / \mathrm{A}$

13. PermitPermit Application No.:

14. Required Response Date:

DATA TRANSMITTED

Mt

\begin{tabular}{l|l|l} 
(C) Sheet & (D) Rev. & (E) Title or Description of Data Transmitted \\
No. & (E)
\end{tabular}

(F) Appror

\begin{tabular}{|c|c|c|c|}
\hline $\begin{array}{c}\text { Approval } \\
\text { Desig- } \\
\text { nator }\end{array}$ & $\begin{array}{l}\text { Reason } \\
\text { for Trans- } \\
\text { mital }\end{array}$ & $\begin{array}{c}\text { Origi- } \\
\text { nator } \\
\text { Dispo- } \\
\text { sition. }\end{array}$ & $\begin{array}{l}\text { Receiv- } \\
\text { er } \\
\text { Dispo- } \\
\text { sition }\end{array}$ \\
\hline & & & \\
\hline
\end{tabular}

\begin{tabular}{|l}
\hline 1 \\
\hline 15 \\
\hline 16 \\
\hline
\end{tabular}

\begin{tabular}{|c|c|}
\hline Approval Designator (F) & \\
\hline E. S, Q D OR N/A & 1. Approval \\
(See WHC-CM-5;, & 2. Release \\
Sec. 12.7) & 3. Intormation
\end{tabular}

17.

$$
\begin{aligned}
& \hline 1 \\
& \hline \\
& \hline \\
& \hline \\
& \hline \\
& \hline \\
& \hline 16 \\
& \hline
\end{aligned}
$$$$
1 \quad \text { SNE-3896 }
$$

\begin{tabular}{l}
\hline \\
\hline \\
\hline \\
\hline \\
\hline \\
\hline \\
\hline \\
\hline \\
\hline
\end{tabular}

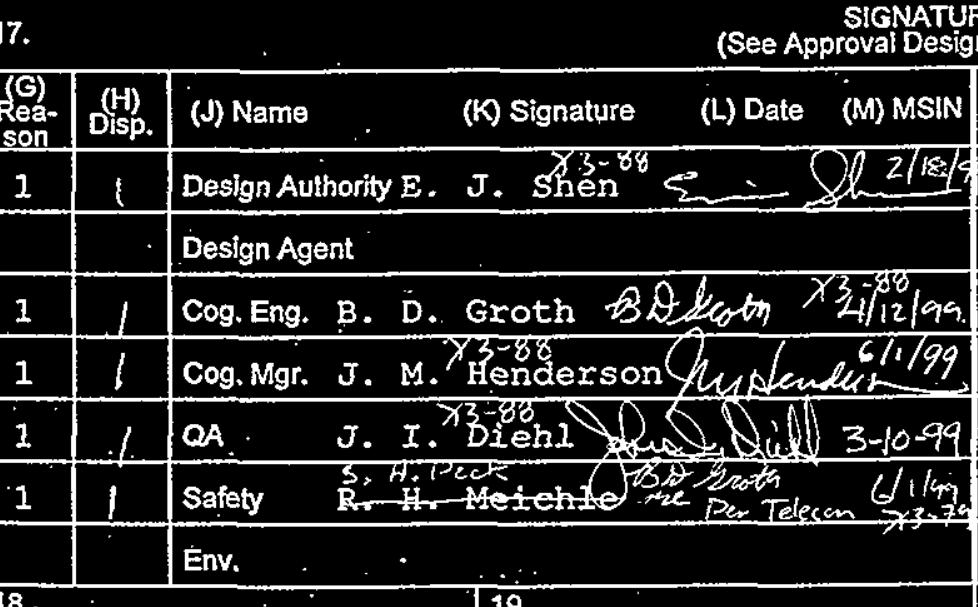

$$
\text { ¿. }
$$

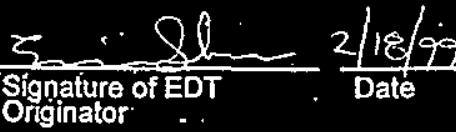

Reason for Transmittal (G)

4. Review
5. Post-Review
6. Dist. (Receipt Acknow. Required)

4. Review

6. Dist. (Receipt Acknow. Required)

KEY

\begin{tabular}{l} 
Fuel Retrieval System \\
Process Valiadion \\
Procedures \\
\hline
\end{tabular}

\begin{tabular}{|l|l|l|}
\hline S\&Q & 1 & \\
\hline & & \\
\hline & & \\
\hline & & \\
\hline & & \\
\hline & & \\
\hline & & \\
\hline
\end{tabular}

Disposition (H) \& (1)

$\begin{array}{ll}\text { 1. Approved } & \text { 4. Reviewed no/comment } \\ \text { 3. Approved w/comment } & \text { 5. Reviewed w/comment } \\ \text { 3. Disapproved w/comment } & \text { 6. Recelpt acknowledged }\end{array}$
SIGNATUREJOISTRIBUTION (See Approval Designator for required signatures)
(SITAT 


\title{
FUEL RETRIEVAL SYSTEM PROCESS VALIDATION PROCEDURE
}

\author{
E.J. Shen, A.I. Pajunen, T.L. Welsh \\ DESH \\ Richland, WA 99352 \\ U.S. Department of Energy Contract DE-AC06-96RL13200 \\ EDT/ECN: 626040 \\ UC: 2050 \\ Org Code: D1350000 \\ Charge Code: 105497 \\ B\&R Code: EW7040000 \\ Total Pages: 38
}

Key Words: FRS, Process Validation, Fuel Cleaning, Sampling Sludge, Removal

Abstract: The FRS process validation procedure is focused upon cleaning NReactor Spent Fuel of corrosion products using a statistical process control approach to cleaning parameters.

Trademark Information: Ford is a registered trademark of Ford Motor Co., Dearborn, Michigan.

TRADEMARK DISCLAIMER. Reference herein to any specific commercial product, process, or service by trade name, trademark, manufacturer, or otherwise, does not necessarily constitute or imply its endorsement, recommendation, or favoring by the United States Government or any agency thereof or its contractors or subcontractors.

Printed in the United States of America. To obtain copies of this document, contact: Document Control Services, P.O. Box 950, Mailstop H6-08, Richland WA 99352, Phone (509) 372-2420; Fax (509) 376-4989.
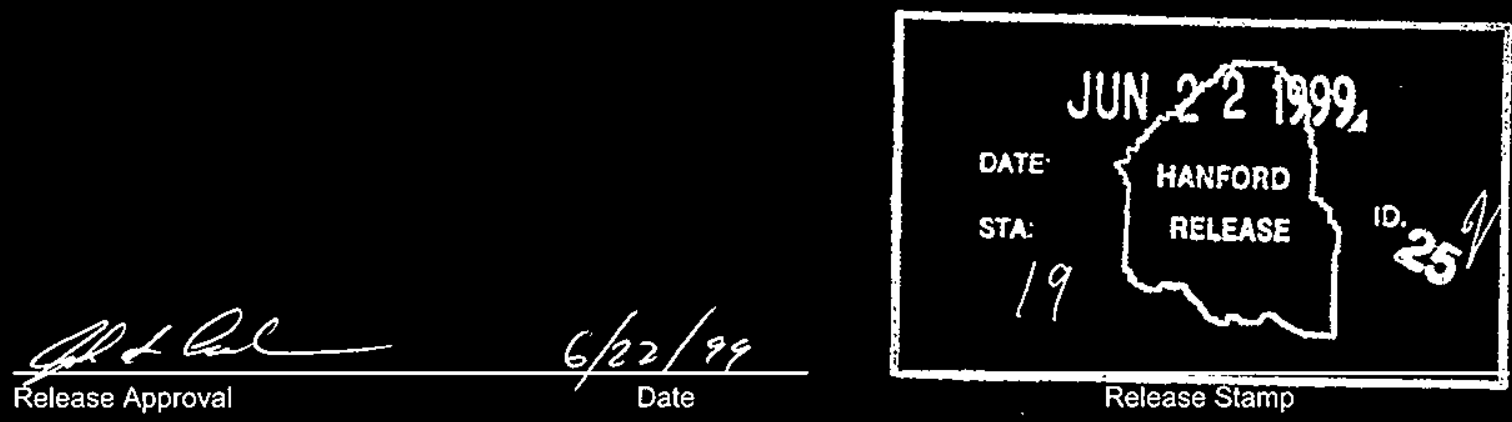
TABLE OF CONTENTS

1.0 INTRODUCTION AND PURPOSE

2.0 SUMMARY

3.0 PHASE I - OPERATIONAL PARAMETER TESTING $\ldots \ldots \ldots \ldots \ldots \ldots \ldots$

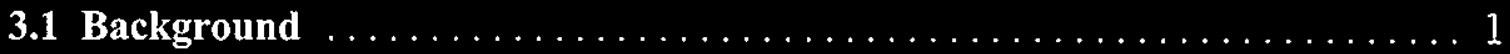

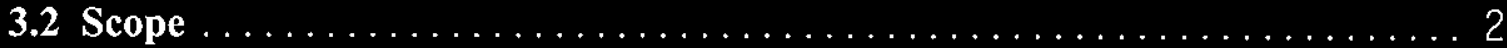

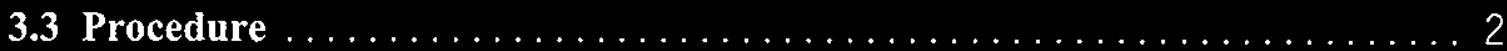

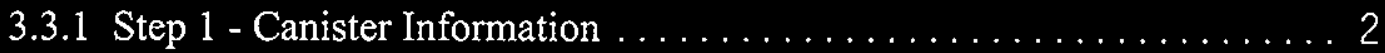

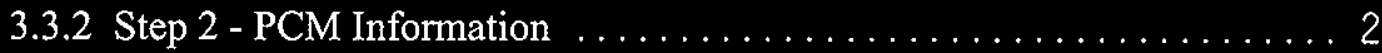

3.3.3 Step 3 - Clean the Fuel ......................... 3

3.3.4 Step 4 - Transfer "Clean" Fuel ....................... 3

3.3.5 Step 5 - Inspect "Clean" Fuel ..................... 3

3.3.5.1 All "Clean" Fuel .......................... 3

3.3.5.2 "Not Clean" Fuel ......................... 4

3.3.6 Step 6 - Disposition of "Clean" Fuel . ................... 4

3.3.7 Step 7 - Disposition of Material in Scrap Baskets .............. 5

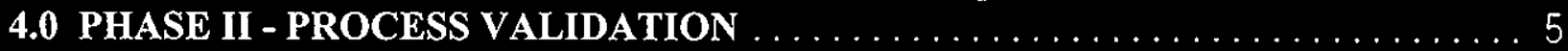

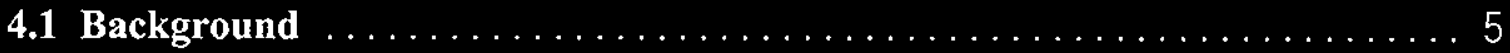

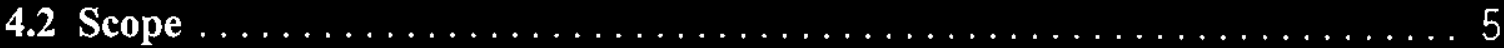

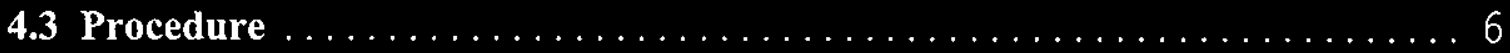

4.3.1 Step 1 - Canister Selection $\ldots \ldots \ldots \ldots \ldots \ldots \ldots \ldots \ldots \ldots \ldots$

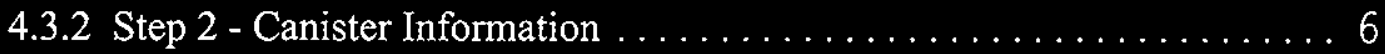

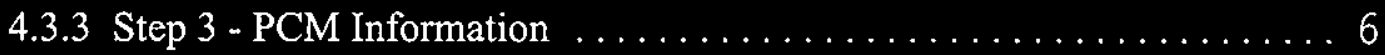

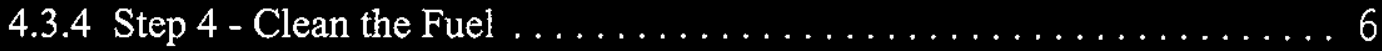

4.3.5 Step 5 -Transfer "Clean" Fuel . . . . . . . . . . . . . . . . . . 6

4.3.6.1 All "Clean" Fuel .......................... 6

4.3.6.2 "Not Clean" Fuel . . . . . . . . . . . . . . . . . . . . . 7

4.3.7 Step 7 - Disposition of "Clean" Fuel .................... 7

4.3.8 Step 8 - Disposition of Material in Scrap Baskets .............. 8

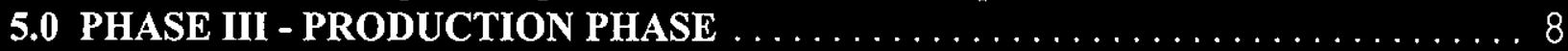

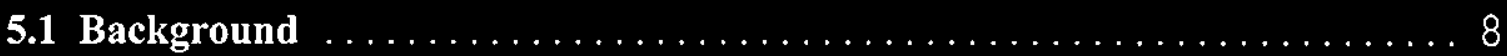

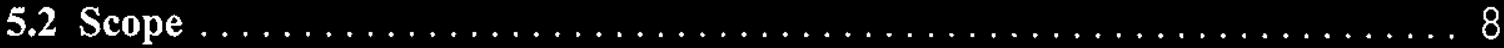

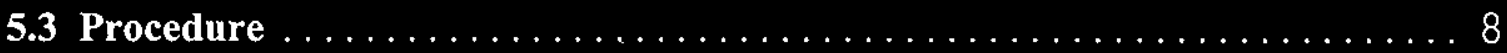

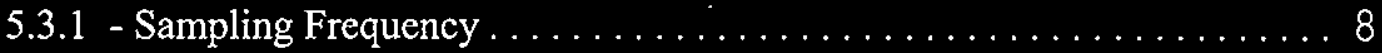

5.3.2 - Canister Information. . . . . . . . . . . . . . . . . . . . 9

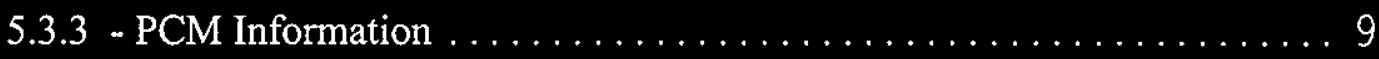

5.3 .4 - Clean the Fuel ........................... 9 
5.3.5 - Transfer "Clean" Fuel . . . . . . . . . . . . . . . . . . . . . . . . 9

5.3.6 - Inspect "Clean" Fuel ............................. 9

5.3.6.1 - All "Clean" Fuel ............................. . 9

5.3.6.2 - "Not Clean" Fuel . . . . . . . . . . . . . . . . . . . . 9

5.3.6.2.1 - Process Review ................... 10

5.3.6.2.2 - Process Actions . . . . . . . . . . . . . . . . . . 10

5.3.7 Step 7 - Disposition of "Clean" Fuel ................... 10

5.3.8 Step 8 - Disposition of Material in Scrap Baskets . . . . . . . . . . 10

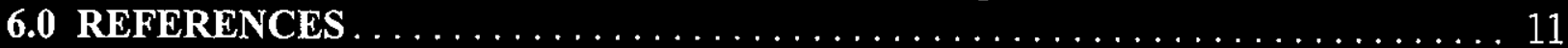

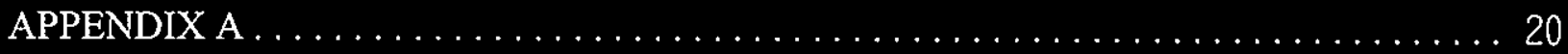

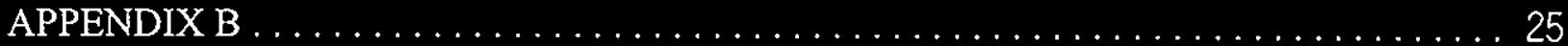

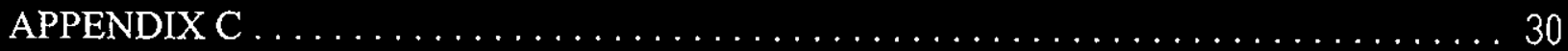




\section{FUEL RETRIEVAL SYSTEM PROCESS VALIDATION PROCEDURE}

\subsection{INTRODUCTION AND PURPOSE}

A key element in the Fuel Retrieval System (FRS) of the Spent Nuclear Fuel (SNF) Project is the removal of sludge from the exterior of the SNF prior to its placement in a Multi-canister Overpack (MCO) basket for drying and cleaning operations. The process of removing the SNF from the storage locations in the $\mathrm{K}$ East and $\mathrm{K}$ West Basins, has the following steps: SNF is moved from storage canisters to the FRS process area, it is sorted, cleaned, and placed in an MCO basket.

Because of the throughput required and the fact that $100 \%$ inspection does not necessarily improve the confidence in product quality, the FRS adopted a process validation methodology which utilizes statistical techniques to assure product quality for the fuel cleaning process. Product quality is needed to prevent undesired chemical reactions with the fuel and to prevent pressurization of the MCO storage container. The process validation approach is based upon the assumption that a first in/first out inventory approach will be used in loading fuel into baskets and baskets into the MCO. The key points in this assumption are to minimize cleaned fuel storage time and minimize impacts upon rework in the event of a failed sample batch. The last point will be further explained later in the document.

This document provides a description of the Fuel Retrieval System (FRS) cleaning process and discusses each step required to validate the FRS cleaning process.

\subsection{SUMMARY}

The FRS process validation procedure consists of three phases. The first phase is to obtain the optimum operating parameter values for the cleaning process. The second phase is to confirm that fuel can be reliably cleaned using the operating parameters established in Phase 1 . The third phase is to assure that the process parameters remain effective in controlling the cleanliness of the SNF during the fuel retrieval campaign.

\subsection{PHASE I - OPERATIONAL PARAMETER TESTING}

\subsection{Background}

The primary cleaning machine will be used to remove the gross sludge from the canisters and fuel by means of mechanical agitation and flushing. A full scale mockup of the primary cleaning station was fabricated and tested at the 305 Building Equipment Testing Laboratory using dummy fuel assemblies with simulant sludge. The objectives of the testing (Ketner and Meeuwsen, 1997) were (1) to evaluate the water flow paths, volumetric flow rates, and nozzle sizes and locations needed to remove sludge from the fuel assemblies effectively, (2) to evaluate the mechanical motions required, with respect to rotation of the wash basket and drop distance of the fuel assembly in the basket, and (3) to evaluate the level of cleanliness accomplished and determine if the primary cleaning system can adequately clean sludge out of the fuel assembly annulus and center hole. 
The primary cleaning system tests (Ketner and Meeuwsen, 1997) demonstrated that sludge can be dislodged and suspended sufficiently to remove it from a fuel canister. The recommended cleaning cycle consists of loading the fuel canister into the wash basket and rotating the fuel clockwise at $4 \mathrm{rpm}$ for 20 minutes while the fuel is allowed to translate a minimum of 4 inches up and down inside the canister. The flush nozzles should each flush continuously at $20 \mathrm{gpm}$ and $225 \mathrm{psig}$, and flush the canister as it passes by the nozzles during each rotation. The discharge flow rate will be set at a nominal $80 \mathrm{gpm}$.

\subsection{Scope}

Fuel will be processed through the cleaning system with the key operating parameters (cleaning cycle time, fuel tumbling cycles, high pressure jet setting and flow rate) set at levels determined from the development test programs (Ketner and Meeuwsen, 1997) which used simulated materials. The results of this phase will (1) determine the initial parameter settings for the second phase and (2) demonstrate that the cleaning process system produces clean fuel.

The cleaning process system will be tested using canisters containing fuel which represent each of the SNF populations (KW Basin and KE Basin). The canister population can be separated into two classes; stainless steel (SS) canisters and aluminum (Al) canisters. The fuel population can be separated into four classes using damage assessment; "intact" fuel, "breached" fuel, "defective" fuel, and "bad" fuel. The definitions of the damage categories are found in Pitner (1998).

Canisters containing fuel which represent the eight categories will be processed through the primary cleaning machine. A category is considered to be represented in a canister if four or more assemblies display the desired properties (e.g., SS and "bad"). Since KW Basin does not have "defective" fuel it is possible, according to this definition, that only two canisters (which contain fuel representing the six categories) will need to be processed in Phase I. Since it is a general consensus that processing only two canisters through the cleaning system is not enough to determine the key operating parameters, a minimum of six canisters will be processed through the primary cleaning machine during Phase I (parameter testing).

\subsection{Procedure}

\subsubsection{Step 1 - Canister Information}

A canister from one of the canister categories is moved to the processing area. The canister location, canister type, damage assessment, and any Safeguards required data (e.g., key, model) are recorded on the data sheet.

\subsubsection{Step 2 - PCM Information}

The primary cleaning machine ( $\mathrm{PCM})$ is verified to be empty. The canister is moved into the PCM basket. 


\subsubsection{Step 3 - Clean the Fuel}

The appropriate wash cycle is selected. The operating parameters (cleaning cycle time, fuel tumbling cycles, high pressure jet setting and flow rate) are recorded on the data sheet. The wash cycle is started.

\subsubsection{Step 4 - Transfer "Clean" Fuel}

After the wash cycle is completed the canister is transferred from the PCM to the the process table and dumped (Shen 1998). The fuel assemblies are then taken to the disassembly station. The total number of assemblies along with the total number of inners and outers is recorded. If the canister contains "stuck" fuel, then another canister containing the same type of SNF is selected and steps 3.3.1 through 3.3.5 are repeated. The disassembly station ram will be used to separate inner from outer elements. If the elements should separate during manipulator transfer to disassembly station, the quantity of sludge dropped on the table shall be measured. Consolidation by scraping is allowed to gather sludge into a measurable pile.

\subsubsection{Step 5 - Inspect "Clean" Fuel}

Each assembly is inspected against the cleaning criteria using a high resolution closed circuit television system to look down the bore of the element. The basis of the cleaning criteria is explained in Appendix A. An assembly fails the cleaning criteria if, when removing the inner element from the outer element, and/or subsequent inspection of both elements, the total quantity of corrosion product (sludge) observed is equivalent to a cone that is 1 -inch in diameter (size of a quarter) at the base and $1 / 3$-inch high. The assembly also fails the cleaning criteria if visual examinations identify a bore obstruction that cannot be attributed to features of the element (e.g., clad defects, clips) or coatings. The assembly either passes the cleaning criteria or fails the cleaning criteria. The number of assemblies which fail the cleaning criteria is recorded.

\subsubsection{All "Clean" Fuel}

If all the assemblies from the canister pass the cleaning criteria, then a canister representing one of the remaining canister categories is selected for cleaning. Steps 3.3.1 through 3.3.5 are repeated until fuel from each of the canister categories has been through the cleaning and examination process. 


\subsubsection{2 "Not Clean" Fuel}

If one or more of the assemblies from a canister fail the cleaning criteria, phase I is stopped. The cleaning process is evaluated to determine the cause of the failure(s). The evaluation may require changes to the operating parameters. After the parameter adjustments are completed, another canister containing the same type of SNF is selected and steps 3.3.1 through 3.3.5 are repeated.

Once a canister category has passed the cleaning criteria, no repeats are needed as long as the operating parameter changes are more aggressive. This assumes that if the PCM process parameters "cleans" fuel with high damage, then the PCM process parameters will "clean" fuel with less damage.

If the cleaning process is unsuccessful, the design authority (DA) shall be notified. The DA will provide a modified procedure or redline the revisions into the control copy of the procedures. The DA will generally implement the process that follows to improve the cleaning process performance:

- Increase the cleaning cycle times in 5 minute increments up to 30 minutes. If cleaning unsatisfactory, then:

c Reset cleaning cycle to 20 minutes and increase basket rotation speed to $5 \mathrm{rpm}$. If cleaning unsatisfactory, decrease rotation speed to $3 \mathrm{rpm}$. If cleaning unsatisfactory, select the speed producing the best cleaning action and increase flow to cleaning jets.

c Increase flow through cleaning jets to $25 \mathrm{gpm} /$ nozzle. This will most likely require nozzles of a different configuation to be used.

\subsubsection{Step 6 - Disposition of "Clean" Fuel}

All elements (inners and outers) which pass the cleaning criteria are either loaded into either a fuel or scrap basket or placed back in the canister for storage in the basin depending on fuel campaign requirements. During Phase I all elements which fail the cleaning criteria will be moved to the secondary cleaning station for manual brushing prior to placement in a fuel/scrap basket or canister.

Once acceptable process settings are verified (fuel assemblieslelements representing each of the canister categories have passed the cleaning criteria), Phase I (Operation Parameter Testing) is complete and Phase II (Process Validation) begins. 


\subsubsection{Step 7 - Disposition of Material in Scrap Baskets}

Bad elements with split clad and missing end caps will be loaded in scrap baskets and will not be evaluated against the cleaning criteria as part of the process validation procedure. This is not required because the bounding quantity of particulate in a scrap basket developed in Sloughter (1998) is large enough to bound the inventory that would be observed if each assembly in a scrap basket were to contain the equivalent of a 3 -inch plug of canister particulate (no effective cleaning); details are provided in Appendix A.

\subsection{PHASE II - PROCESS VALIDATION}

\subsection{Background}

The goal of the validation phase is to confirm that fuel can be reliably cleaned using the key operating parameters established in the Operational Parameter Testing. The amount of sludge associated with "clean" SNF in an MCO is important in order to (1) define worst case radioactive releases from MCOs for postulated accidents and (2) define the amount of water that could potentially exist as hydrated chemical compounds within MCOs (see Sloughter 1998 for details).

\subsection{Scope}

Twenty-nine randomly selected canisters are processed through the cleaning station. If all 29 canisters pass the cleaning criteria, then there is $99 \%$ confidence that at least $85 \%$ of the total population (either $\mathrm{KE}$ canisters or $\mathrm{KW}$ canisters) will also pass the cleaning criteria. This implies that there could be approximately $15 \%$ of the total population (either $\mathrm{KW}$ canisters or $\mathrm{KE}$ canisters) that may not pass the cleaning criteria. This does not mean that every assembly in the $15 \%$ of the population will fail the cleaning criteria. It means there is a risk that a proportion of the population may contain quantities of sludge in excess of process validation detection limits.

If twenty-nine canisters are processed during the process validation test batch and each canister contains 14 assemblies, then $406(29 * 14)$ assemblies will have been cleaned and examined. If three assemblies [out of approximately $406(29 * 14)$ assemblies] in the process validation test batch ( 29 canisters) fail the assembly cleaning criteria, then the batch fails the process validation test. By recording the number of assemblies which fail the cleaning criteria out of the total number of assemblies examined from each of the 29 canisters, an estimate of the true proportion of the assemblies which fail the cleaning criteria in the canister population can be calculated.

The equation used to calculate the sample size is provided in Appendix B. Table 1 of Appendix B provides the sample size calculations for the $\mathrm{KW}$ canister population varying the equation parameters. Table 2 of Appendix B provides the sample size calculations for the KE canister population varying the equation parameters. 


\subsection{Procedure}

4.3.1 Step 1 - Canister Selection

Twenty-nine canisters are randomly selected from the KW (or KE) canister population.

\subsubsection{Step 2 - Canister Information}

One of the 29 canisters is moved to the processing area. The canister location, canister type, damage assessment, and any safeguards required data are recorded on the data sheet.

\subsubsection{Step 3 - PCM Information}

The PCM is verified to be empty. The canister is moved into the PCM basket.

\subsubsection{Step 4 - Clean the Fuel}

The appropriate wash cycle is selected. The operating parameters (cleaning cycle time, fuel tumbling cycles, high pressure jet setting and flow rate) are recorded on the data sheet. The wash cycle is started.

\subsubsection{Step 5 -Transfer "Clean" Fuel}

After the wash cycle is completed the canister is transferred from the PCM to the process table and dumped (Shen 1998). The fuel assemblies are then taken to the disassembly station. The total number of assemblies along with the total number of inners and outers is recorded.

\subsubsection{Step 6 - Inspect "Clean" Fuel}

Each assembly is inspected against the cleaning criteria using a high resolution closed circuit television system. The basis of the cleaning criteria is explained in Appendix A. An assembly fails the cleaning criteria if, when removing the inner element from the outer element, and/or subsequent inspection of both elements, the total quantity of corrosion product (sludge) observed is equivalent to a cone that is 1 -inch in diameter (size of a quarter) at the base and $1 / 3$-inch high. The assembly either passes the cleaning criteria or fails the cleaning criteria. The number of assemblies which fail the cleaning criteria is recorded.

\subsubsection{All "Clean" Fuel}

If all the assemblies from the canister pass the cleaning criteria, then another canister from the population of 29 is selected for cleaning. Steps 
4.3.1 through 4.3.6 are repeated until all of the 29 randomly selected canisters have been through the cleaning and examination process.

\subsubsection{2 "Not Clean" Fuel}

If one assembly in a canister fails the assembly cleaning criteria and no other assemblies have failed the cleaning criteria, then the canister passes the cleaning criteria. However, there can be no more than one more assembly in the canister batch (the 29 randomly selected canisters) that fails the assembly cleaning criterion. See Appendix A for details regarding the cleaning criteria.

If two assemblies in a canister fail the assembly cleaning criteria and no other assemblies have failed the cleaning criteria, then the canister passes the canister cleaning criteria. However, no more assemblies in the canister batch can fail the assembly cleaning criteria.

If three assemblies in a process validation test batch fail the assembly cleaning criteria, then the batch fails the process validation test.

If the process validation test fails, the process will be reviewed to ascertain the cause of the failure (e.g., does the particular canister(s) with the assemblies that caused the failures contain an abnormal number of fuel elements with extreme or difficult to clean fuel). Corrective actions could entail revising the process parameters and restarting either the operating parameter testing or the validation phase. (See 3.3.6)

Once the process validation test fails (a third assembly fails the cleaning criteria), the remaining fuel can either be reprocessed through the PCM or sent to the secondary cleaning station for manual brushing.

\subsubsection{Step 7 - Disposition of "Clean" Fuel}

The number of assemblies from each of the 29 canisters which fail the cleaning criteria is recorded. The total number of assemblies which fail the cleaning criteria is restricted to less than or equal to two assemblies or the process validation batch (Phase II) fails. All elements (inners and outers) will be placed in a fuel basket, a scrap basket, or placed into a canister and returned to storage.

Once Phase II (Process Validation) is completed (fuel can be reliably cleaned using the established criteria/parameters), Phase III (Production Phase) begins. 


\subsubsection{Step 8 - Disposition of Material in Scrap Baskets}

Bad elements with split clad and missing end caps will be loaded in scrap baskets and will not be evaluated against the cleaning criteria as part of the process validation procedure (see section 3.3.7 for details).

\subsection{PHASE III - PRODUCTION PHASE}

\subsection{Background}

Following completion of process validation, FRS will enter the production phase (Phase III). During production, separation and inspection are bypassed and fuel is loaded directly into baskets. Periodic sampling is employed to maintain quality control.

Phase III (Production Phase) uses an ongoing process based upon Statistical Process Control (SPC) methods as explained in Ford (1984). Phase III will be applied during the fuel retrieval campaign to assure that the process parameters remain effective in controlling the cleanliness of the SNF. This will involve periodic sampling where the SNF will be subjected to the same level of scrutiny (cleanliness) as the Validation phase (Phase II).

After the wash cycle is completed the canister is transferred from the PCM to the process table and dumped (Shen 1998). The fuel assemblies are then taken to the disassembly station. The total number of assemblies along with the total number of inners and outers is recorded.

If a canister is found to contain stuck fuel during sampling, that canister will be set aside and another canister will be selected. The basis for this approach is that stuck fuel canisters will be handled and cleaned in a unique manner which is not representative of the normal fuel cleaning process.

\subsection{Scope}

To assure that the process parameters remain effective in controlling the cleanliness of the SNF during the fuel retrieval campaign, periodic sampling in conjunction with SPC methodology will be utilized. The selected sampling interval balances the risk associated with the failure of the canister and the need to maximize production. In other words, how much rework can be tolerated without significant impact to the downstream processes. An SPC failure will require all loaded fuel processed since the last successful periodic sample inspection to be inspected and/or cleaned.

\subsection{Procedure}

\subsection{1 - Sampling Frequency}

One canister per every ten processed canisters will be selected for $100 \%$ fuel separation and inspection against the cleaning criteria specified in Phase II (section 4.3.6). 


\subsection{2 - Canister Information}

The canister is moved to the processing area. The canister location, canister type, damage assessment, and any safeguards required data are recorded on the data sheet.

\subsection{3 - PCM Information}

The PCM is verified to be empty. The canister is moved into the PCM basket.

\subsection{4 - Clean the Fuel}

The operating parameters (cleaning cycle time, fuel tumbling cycles, high pressure jet setting and flow rate) are recorded on the data sheet. The wash cycle is started.

\subsection{5 - Transfer "Clean" Fuel}

After the wash cycle is completed the canister is transferred from the PCM to the process table and dumped (Shen 1998). The fuel assemblies are then taken to the disassembly station. The total number of assemblies along with the total number of inners and outers is recorded.

\subsection{6 - Inspect "Clean" Fuel}

Each assembly is inspected against the cleaning criteria using a high resolution closed circuit television system. An assembly fails the cleaning criteria if, when removing the inner element from the outer element, and/or subsequent inspection of both elements, the total quantity of corrosion product (sludge) observed is equivalent to a cone that is 1-inch in diameter (size of a quarter) at the base and $1 / 3$-inch high. The assembly either passes the cleaning criteria or fails the cleaning criteria. The number of assemblies which fail the cleaning criteria is recorded in order to update the estimate of the defective population.

\subsubsection{1 - All "Clean" Fuel}

If all the assemblies from the canister pass the cleaning criteria, then there is assurance that the process parameters are effective in controlling the cleanliness of the SNF.

\subsubsection{2 - "Not Clean" Fuel}

If one or more of the assemblies from the canister fail the cleaning criteria, then the proportion of failures is outside the upper control limit of the SPC chart where the warning/control limits are based on data obtained in Phase II (details provided in Appendix C). 
SNF-3896, Rev. 0

\subsubsection{1 - Process Review}

If the number of failures is outside the upper control limit, the cleaning process is stopped and the process is reviewed to ascertain the cause of the failure.

Some steps in the process review are as follows. Perform a check on the data (visual observations). Check the process parameters to see (1) if they were within administratively determined tolerance limits and (2) if any changes occurred. Check the historical data for the canister fuel; were any abnormalities observed in the fuel prior to processing, is this a "new" type of fuel that the process hasn't seen yet.

\subsubsection{2 - Process Actions}

If nothing unusual is found in the process review, two additional canisters will be selected for $100 \%$ fuel separation and inspection against the cleaning criteria specified in Phase II (section 4.3.6).

If the results of the two additional canisters are not within statistical control, an SPC failure is declared and the cleaning process is stopped. All batches since the last monitored control sample would be recycled through the inspection process and cleaned. (Thus, the sampling frequency is dependent on how long a period is allowed for rework.)

Corrective actions prior to restarting the Production Phase could entail revising the process parameters and restarting either the operating parameter testing or the validation phase.

\subsubsection{Step 7 - Disposition of "Clean" Fuel}

All elements (inners and outers) will be placed either in a fuel basket or a scrap basket. All elements which fail the cleaning criteria may be moved to the secondary cleaning station for manual brushing prior to placement in a fuel basket.

\subsubsection{Step 8 - Disposition of Material in Scrap Baskets}

Bad elements with split clad and missing end caps will be loaded in scrap baskets and will not be evaluated against the cleaning criteria as part of the process validation procedure (see section 3.3.7 for details). 
SNF-3896, Rev. 0

\subsection{REFERENCES}

Bowen (1988), W. M. and Bennett, C. A., Statistical Methods for Nuclear Material Management, NUREG/CR-4604, PNL-5849,December 1988.

Ford (1984), Continuing Process Control and Process Capability Improvement (A guide to the use of control charts for Improving quality and productivity), Ford Motor Company, published September 1985.

Ketner (1997), G. L. and Meeuwsen, P. V., Final Report Spent Nuclear Fuel Retrieval System Primary Cleaning Development Testing, PNNL-11422, UC-721, September 1997.

Pitner (1998), A. L., Summary Assessment of Fuel Damage Distributions in the K Basins, HNF-2586, Rev. 0, April 1998.

Shen (1998), E. J., Kiebel, G. R., and Jackson, D. R., Fuel Retrieval Sub-Project Process Description, Internal Memo 98EJS001, January 1998.

Sloughter (1998), J. P., Estimates of Particulate Mass in Multi-Canister Overpacks, HNF-1527, Rev. 2, October 1998. 
SNF-3896, Rev. 0

FRS CLEANING PROCESS DATA SHEET

PHASE I - OPERATIONAL PARAMETER TESTING

Date:

Time:

CANISTER IO:

CANISTER \# 1 INFORMATION

Canister Type: Mark I Aluminum, Mark I Stainless Steel.

Fuel Type: MKIV.

MKIA.

Mark II Stainless Steel

Key Number:

OPERATING PARAMETERS

Cleaning Cycle Time =

minutes

Canister Rotation Speed:
High Pressure Flush Nozzles Flow Rate:

Flush Nozzles Pressure:

psig

gpm

Discharge Flow Rate ( 80 gpm or better):

\begin{tabular}{|c|c|c|c|c|c|c|c|c|}
\hline \multirow{2}{*}{ Assembiy } & \multirow{2}{*}{ Inner/Outer } & \multicolumn{4}{|c|}{ Fuel Condition } & \multicolumn{2}{|c|}{ Inspection Results } & \multirow{2}{*}{$\begin{array}{c}\text { Inspected } \\
\text { by }\end{array}$} \\
\hline & & Intact & Breached & Defective & Bad & Clean & Not Clean & \\
\hline \multirow{2}{*}{\multicolumn{9}{|c|}{1}} \\
\hline & & & & & & & & \\
\hline \multirow{2}{*}{\multicolumn{9}{|c|}{2}} \\
\hline & & & & & & & & \\
\hline \multirow{2}{*}{\multicolumn{9}{|c|}{3}} \\
\hline & & & & & & & & \\
\hline \multirow{2}{*}{\multicolumn{9}{|c|}{4}} \\
\hline & & & & & & & & \\
\hline \multicolumn{9}{|l|}{5} \\
\hline & & & & & & & & \\
\hline \multicolumn{9}{|l|}{6} \\
\hline \multirow{2}{*}{\multicolumn{9}{|c|}{7}} \\
\hline & & & & & & & & \\
\hline \multicolumn{9}{|l|}{8} \\
\hline \multirow{2}{*}{\multicolumn{9}{|c|}{9}} \\
\hline & & & & & & & & \\
\hline \multirow{2}{*}{\multicolumn{9}{|c|}{10}} \\
\hline & & & & & & & & \\
\hline \multirow{2}{*}{\multicolumn{9}{|c|}{11}} \\
\hline & & & & & & & & \\
\hline \multicolumn{9}{|l|}{12} \\
\hline \multirow{2}{*}{\multicolumn{9}{|c|}{13}} \\
\hline & & & & & & & & \\
\hline 14 & & & & & & & & \\
\hline & & & & & & & & \\
\hline & & & & & & & & \\
\hline
\end{tabular}

NOTE: A minimum of 4 of each canister type versus fuel condition must pass the cleaning criteria 
SNF-3896, Rev. 0

FRS CLEANING PROCESS DATA SHEET

PHASE I - OPERATIONAL PARAMETER TESTING

Date: Time:

CANISTER ID:

CANISTER \#.2 INFORMATION

Canister Type: Mark I Aluminum. Mark I Stainless Steel.

Fuel Type: MKIV. MKIA. SPR, NAT

Key Number:

OPERATING PARAMETERS

Cleaning Cycle Time $=$ minutes

Canister Rotation Speed:

High Pressure Flush Nozzles Flow Rate:

Flush Nozzles Pressure:

Discharge Flow Rate ( 80 gpm or better):

rom

psig

gpm

\begin{tabular}{|c|c|c|c|c|c|c|c|c|}
\hline \multirow{2}{*}{ Assembly } & \multirow{2}{*}{ Inner/Outer } & \multicolumn{4}{|c|}{ Fuel Condition } & \multicolumn{2}{|c|}{ Inspection Results } & \multirow{2}{*}{$\begin{array}{c}\text { Inspected } \\
\text { by }\end{array}$} \\
\hline & & Intact & Breached & Defective & Bad & Clean & Not Clean & \\
\hline \multirow{2}{*}{\multicolumn{9}{|c|}{1}} \\
\hline & & & & & & & & \\
\hline \multirow{2}{*}{\multicolumn{9}{|c|}{2}} \\
\hline & & & & & & & & \\
\hline \multirow{2}{*}{\multicolumn{9}{|c|}{3}} \\
\hline & & & & & & & & \\
\hline \multicolumn{9}{|l|}{4} \\
\hline \multirow{2}{*}{\multicolumn{9}{|c|}{5}} \\
\hline & & & & & & & & \\
\hline \multirow{2}{*}{\multicolumn{9}{|c|}{6}} \\
\hline & & & & & & & & \\
\hline \multirow{2}{*}{\multicolumn{9}{|c|}{7}} \\
\hline & & & & & & & & \\
\hline \multicolumn{9}{|l|}{8} \\
\hline & & & & & & & & \\
\hline \multicolumn{9}{|l|}{9} \\
\hline \multirow{2}{*}{\multicolumn{9}{|c|}{10}} \\
\hline & & & & & & & & \\
\hline \multicolumn{9}{|l|}{11} \\
\hline \multirow{2}{*}{\multicolumn{9}{|c|}{12}} \\
\hline & & & & & & & & \\
\hline \multicolumn{9}{|l|}{13} \\
\hline & & & & & & & & \\
\hline 14 & & & & & & & & \\
\hline & & & & & Total & & & \\
\hline
\end{tabular}


SNF-3896, Rev. 0

NOTE: A minimum of 4 of each canister type versus fuel condition must pass the cleaning criteria

FRS CLEANING PROCESS DATA SHEET

PHASE I - OPERATIONAL PARAMETER TESTING

Oate: Time:

CANISTER ID:

CANISTER \# 3 INFORMATION

Canister Type: Mark I Aluminum, Mark I Stainless Steel. Mark II Stainless Steel

Fuel Type: MKIV. MKIA. SPR. NAT

Key Number:

OPERATING PARAMETERS

Cleaning Cycle Time -

minutes

Canister Rotation Speed: $\longrightarrow$ rom

High Pressure Flush Nozzles Flow Rate:

Flush Nozzles Pressure:

Oischarge Flow Rate ( 80 gpm or better):

gpm

\begin{tabular}{|c|c|c|c|c|c|c|c|c|}
\hline \multirow{2}{*}{ Assembly } & \multirow[b]{2}{*}{ Inner/Outer } & \multicolumn{4}{|c|}{ Fuel Condition } & \multicolumn{2}{|c|}{ Inspection Results } & \multirow{2}{*}{$\begin{array}{c}\text { Inspected } \\
\text { by }\end{array}$} \\
\hline & & Intact & Breached & Defective & Bad & Clean & Not Clean & \\
\hline \multirow{2}{*}{\multicolumn{9}{|c|}{1}} \\
\hline & & & & & & & & \\
\hline \multicolumn{9}{|l|}{2} \\
\hline & & & & & & & & \\
\hline \multirow{2}{*}{\multicolumn{9}{|c|}{3}} \\
\hline & & & & & & & & \\
\hline \multirow{2}{*}{\multicolumn{9}{|c|}{4}} \\
\hline & & & & & & & & \\
\hline \multicolumn{9}{|l|}{5} \\
\hline \multirow{2}{*}{\multicolumn{9}{|c|}{6}} \\
\hline & & & & & & & & \\
\hline \multicolumn{9}{|l|}{7} \\
\hline & & & & & & & & \\
\hline \multicolumn{9}{|l|}{8} \\
\hline \multirow{2}{*}{\multicolumn{9}{|c|}{9}} \\
\hline & & & & & & & & \\
\hline \multicolumn{9}{|l|}{10} \\
\hline \multirow{2}{*}{\multicolumn{9}{|c|}{11}} \\
\hline & & & & & & & & \\
\hline \multicolumn{9}{|l|}{12} \\
\hline & & & & & & & & \\
\hline \multicolumn{9}{|l|}{13} \\
\hline \multirow{2}{*}{\multicolumn{9}{|c|}{14}} \\
\hline & & & & & & & & \\
\hline & & & & & Total & & & \\
\hline
\end{tabular}


SNF-3896, Rev. 0

NOTE: A minimum of 4 of each canister type versus fuel condition must pass the cleaning criteria

FRS CLEANING PROCESS DATA SHEET

PHASE I - OPERATIONAL PARAMETER TESTING

Date:

Time:

CANISTER I0:

CANISTER \# 4 INFORMATION

Canister Type: Mark I Aluminum, Mark I Stainless Stee]. Mark II Stainless Steel

Fuel Type: MKIV. MKIA, SPR, NAT

Key Number:

OPERATING PARAMETERS

Cleaning Cycle Time $=$

minutes

Canister Rotation Speed:

High Pressure Flush Nozzles Flow Rate:

Flush Nozzles Pressure:

Discharge Flow Rate ( 80 gpm or better):

rpm

psig

gpm

\begin{tabular}{|c|c|c|c|c|c|c|c|c|}
\hline \multirow[b]{2}{*}{ Assembly } & \multirow[b]{2}{*}{ Inner/Outer } & \multicolumn{4}{|c|}{ Fuel Condition } & \multicolumn{2}{|c|}{ Inspection Results } & \multirow{2}{*}{$\begin{array}{c}\text { Inspected } \\
\text { by }\end{array}$} \\
\hline & & Intact & Breached & Defective & $\mathrm{Bad}$ & Clean & Not Clean & \\
\hline \multirow{2}{*}{1} & & & & & & & & \\
\hline & & & & & & & & \\
\hline \multirow{2}{*}{2} & & & & & & & & \\
\hline & & & & & & & & \\
\hline \multirow{2}{*}{3} & & & & & & & & \\
\hline & & & & & & & & \\
\hline \multirow{2}{*}{4} & & & & & & & & \\
\hline & & & & & & & & \\
\hline \multirow{2}{*}{5} & & & & & & & & \\
\hline & & & & & & & & \\
\hline \multirow{2}{*}{6} & & & & & & & & \\
\hline & & & & & & & & \\
\hline \multirow{2}{*}{7} & & & & & & & & \\
\hline & & & & & & & & \\
\hline \multirow[t]{2}{*}{8} & & & & & & & & \\
\hline & & & & & & & & \\
\hline \multirow[t]{2}{*}{9} & & & & & & & & \\
\hline & & & & & & & & \\
\hline \multirow{2}{*}{10} & & & & & & & & \\
\hline & & & & & & & & \\
\hline \multirow[t]{2}{*}{11} & & & & & & & & \\
\hline & & & & & & & & \\
\hline \multirow{2}{*}{12} & & & & & & & & \\
\hline & & & & & & & & \\
\hline \multirow{2}{*}{13} & & & & & & & & \\
\hline & & & & & & & & \\
\hline \multirow[t]{2}{*}{14} & & & & & & & & \\
\hline & & & & & & & & \\
\hline & & & & & Total & & & \\
\hline
\end{tabular}


NOTE: A minimum of 4 of each canister type versus fuel condition must pass the cleaning criteria

FRS CLEANING PROCESS DATA SHEET

PHASE I - OPERATIONAL PARAMETER TESTING

Date: Time:

CANISTER ID:

CANISTER \# 5 INFORMATION

Canister Type: Mark I Aluminum. Mark I Stainless Steel. Mark II Stainless Steel
Fuel Type: MKIV. MKIA. SPR, NAT

Key Number:

OPERATING PARAMETERS

Cleaning Cycle Time =

minutes

Canister Rotation Speed:

High Pressure Flush Nozzles Flow Rate:

Glush Nozzles Pressure:

rpm

psig

gpm

Discharge flow Rate ( 80 gpm or better):

\begin{tabular}{|c|c|c|c|c|c|c|c|c|}
\hline \multirow[b]{2}{*}{ Assembly } & \multirow[b]{2}{*}{ Inner/Outer } & \multicolumn{4}{|c|}{ Fuel Condition } & \multicolumn{2}{|c|}{ Inspection Results } & \multirow{2}{*}{$\begin{array}{c}\text { Inspected } \\
\text { by }\end{array}$} \\
\hline & & Intact & Breached & Defective & Bad & Clean & Not Clean & \\
\hline \multicolumn{9}{|l|}{1} \\
\hline & & & & & & & & \\
\hline \multicolumn{9}{|l|}{2} \\
\hline & & & & & & & & \\
\hline \multicolumn{9}{|l|}{3} \\
\hline & & & & & & & & \\
\hline \multicolumn{9}{|l|}{4} \\
\hline & & & & & & & & \\
\hline \multicolumn{9}{|l|}{5} \\
\hline \multirow{2}{*}{\multicolumn{9}{|c|}{6}} \\
\hline & & & & & & & & \\
\hline \multicolumn{9}{|l|}{7} \\
\hline & & & & & & & & \\
\hline \multicolumn{9}{|l|}{8} \\
\hline \multirow{2}{*}{\multicolumn{9}{|c|}{ 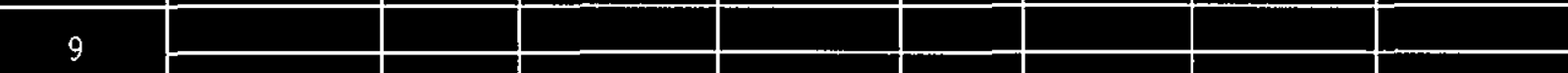 }} \\
\hline & & & & . & & & & \\
\hline \multicolumn{9}{|l|}{10} \\
\hline 10 & & & & & & & & \\
\hline \multicolumn{9}{|l|}{11} \\
\hline \multirow{2}{*}{\multicolumn{9}{|c|}{12}} \\
\hline & & & & & & & & \\
\hline \multirow{2}{*}{\multicolumn{9}{|c|}{13}} \\
\hline & & & & & & & & \\
\hline 14 & & & & & & & & \\
\hline & & & & & Total & & & \\
\hline
\end{tabular}


SNF-3896, Rev. 0

NOTE: A minimum of 4 of each canister type versus fuel condition must pass the cleaning criteria

FRS CLEANING PROCESS DATA SHEET

PHASE I - OPERATIONAL PARAMETER TESTING

Date:_ Time:_ CANISTER IO:

CANISTER \# 6 INFORMATION

Canister Type: Mark I Aluminum, Mark I Stainless Steel, Mark II Stainless Steel
Fuel Type: MKIV. MKIA. SPR. NAT

Key Number:

OPERATING PARAMETERS

Cleaning Cycle Time $=$

minutes

Canister Rotation Speed:

High Pressure Flush Nozzles Flow Rate:

Flush Nozzles Pressure:

Discharge Flow Rate (80 gpm or better):

rom

psig

\begin{tabular}{|c|c|c|c|c|c|c|c|c|}
\hline \multirow[b]{2}{*}{ Assembly } & \multirow[b]{2}{*}{ Inner/Outer } & \multicolumn{4}{|c|}{ Fuel Condition } & \multicolumn{2}{|c|}{ Inspection Results } & \multirow{2}{*}{$\begin{array}{c}\text { Inspected } \\
\text { by }\end{array}$} \\
\hline & & Intact & Breached & Defective & Bad & Clean & Not Clean & \\
\hline \multicolumn{9}{|l|}{1} \\
\hline & & & & & & & & \\
\hline \multicolumn{9}{|l|}{2} \\
\hline 6 & & & & & & & & \\
\hline \multirow{2}{*}{\multicolumn{9}{|c|}{3}} \\
\hline & & & & & & & & \\
\hline \multicolumn{9}{|l|}{4} \\
\hline & & & & & & & & \\
\hline \multicolumn{9}{|l|}{5} \\
\hline \multirow{2}{*}{\multicolumn{9}{|c|}{6}} \\
\hline & & & & & & & & \\
\hline \multicolumn{9}{|l|}{7} \\
\hline & & & & & & & & \\
\hline \multicolumn{9}{|l|}{8} \\
\hline ( & & & & & & & & \\
\hline \multicolumn{9}{|l|}{9} \\
\hline & & & & & & & & \\
\hline \multicolumn{9}{|l|}{10} \\
\hline \multirow{2}{*}{\multicolumn{9}{|c|}{11}} \\
\hline & & & & & & & & \\
\hline \multicolumn{9}{|l|}{12} \\
\hline \multirow{2}{*}{\multicolumn{6}{|c|}{13}} & & 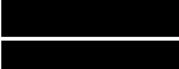 & \\
\hline & & & & & & & & \\
\hline 14 & & & & & & & & \\
\hline & & & & & 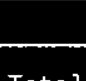 & & & \\
\hline
\end{tabular}


SNF-3896, Rev. 0

NOTE: A minimum of 4 of each canister type versus fuel condition must pass the cleaning criteria

FRS CLEANING PROCESS DATA SHEET

PHASE II - PROCESS VALIDATION

Oate:

Time:

CANISTER I0:

CANISTER \# INFORMATION

Canister Type: Mark I Aluminum. Mark I Stainless Steel, Mark II Stainless Steel
Fuel Type: MKIV. MKIA. SPR. NAT

Key Number:

OPERATING PARAMETERS

Cleaning Cycle Time $=$

minutes

Canister Rotation Speed:

High Pressure Flush Nozzles Flow Rate:

Flush Nozzles Pressure:

Discharge Flow Rate ( $80 \mathrm{gpm}$ or better): rpm

psig

gpm

\begin{tabular}{|c|c|c|c|c|c|c|c|c|}
\hline \multirow[b]{2}{*}{ Assemb7y } & \multirow[b]{2}{*}{ Inner/Outer } & \multicolumn{4}{|c|}{ Fuel Condition } & \multicolumn{2}{|c|}{ Inspection Results } & \multirow{2}{*}{$\begin{array}{c}\text { Inspected } \\
\text { by }\end{array}$} \\
\hline & & Intact & Breached & Defective & $\mathrm{Bad}$ & Clean & Not Clean. & \\
\hline \multirow{2}{*}{1} & & & & & & & & \\
\hline & & & & & & & & \\
\hline \multirow[t]{2}{*}{2} & & & & & & & & \\
\hline & & & & & & & & \\
\hline \multirow{2}{*}{3} & & & & & & & & \\
\hline & & & & & & & & \\
\hline \multirow{2}{*}{4} & & & & & & & & \\
\hline & & & & & & & & \\
\hline \multirow{2}{*}{5} & & & & & & & & \\
\hline & & & & & & & & \\
\hline \multirow{2}{*}{6} & & & & & & & & \\
\hline & & & & & & & & \\
\hline \multirow[t]{2}{*}{7} & & & & & & & & \\
\hline & & & & & & & & \\
\hline \multirow[t]{2}{*}{8} & & & & & & & & \\
\hline & & & & & & & & \\
\hline \multirow[t]{2}{*}{9} & & & & & & & & \\
\hline & & & & & & & & \\
\hline \multirow{2}{*}{10} & & & & & & & & \\
\hline & & & & & & & & \\
\hline \multirow[t]{2}{*}{11} & & & & & & & & \\
\hline & & & & & & & & \\
\hline \multirow[t]{2}{*}{12} & & & & & & & & \\
\hline & & & & & & & & \\
\hline \multirow[t]{2}{*}{13} & & & & & & & & \\
\hline & & & & & & & & \\
\hline \multirow[t]{2}{*}{14} & & & & & & & & \\
\hline & & & & & & & & \\
\hline & & & & & Total & & & \\
\hline
\end{tabular}


SNF-3896, Rev. 0

NOTE: A minimum of 29 canisters will be processed during the validation phase

FRS CLEANING PROCESS DATA SHEET

PHASE III - PRODUCTION PHASE

Date: Time : CANISTER 10:

CANISTER INFORMATION

Canister Type: Mark I Aluminum. Mark I Stainless Steel. Mark II Stainless Steel

Fuel Type: MKIV. MKIA. SPR, NAT

Key Number:

OPERATING PARAMETERS

Cleaning Cycle Time -

Canister Rotation Speed: $\longrightarrow$ rom

High Pressure flush Nozzles Flow Rate:

gpm

Flush Nozzles Pressure:

psig

Discharge Flow Rate (80 gpm or better):

\begin{tabular}{|c|c|c|c|c|c|c|c|c|}
\hline \multirow[b]{2}{*}{ Assembly } & \multirow[b]{2}{*}{ Inner/Outer } & \multicolumn{4}{|c|}{ Fuel Condition } & \multicolumn{2}{|c|}{ Inspection Results } & \multirow{2}{*}{$\begin{array}{c}\text { Inspected } \\
\text { by }\end{array}$} \\
\hline & & Intact & Breached & Defective & Bad & Clean & Not Clean & \\
\hline \multicolumn{9}{|l|}{1} \\
\hline & & & & & & & & \\
\hline \multicolumn{9}{|l|}{2} \\
\hline & & & & & & & & \\
\hline \multicolumn{9}{|l|}{3} \\
\hline 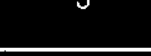 & & & & & & & & \\
\hline \multicolumn{9}{|l|}{4} \\
\hline 4 & & & & & & & & \\
\hline \multicolumn{9}{|l|}{5} \\
\hline 3 & & & & & & & & \\
\hline \multicolumn{9}{|l|}{6} \\
\hline 0 & & & & & & & & \\
\hline \multicolumn{9}{|l|}{7} \\
\hline$f$ & & & & & & & & \\
\hline \multicolumn{9}{|l|}{8} \\
\hline 0 & & & & & & & & \\
\hline \multicolumn{9}{|l|}{9} \\
\hline 3 & & & & & & & & \\
\hline \multicolumn{9}{|l|}{10} \\
\hline 10 & & & & & & & & \\
\hline \multirow{2}{*}{\multicolumn{9}{|c|}{11}} \\
\hline 11 & & & & & & & & \\
\hline \multirow{2}{*}{\multicolumn{9}{|c|}{12}} \\
\hline 16 & & & & & & & & \\
\hline \multicolumn{9}{|l|}{13} \\
\hline 10 & & & & & & & & \\
\hline \multirow{2}{*}{14} & & & & & & & & \\
\hline & & & & & & & & \\
\hline & & & & & Total & & & \\
\hline
\end{tabular}

NOTE: One canister per every ten processed canisters will be selected for $100 \%$ fuel separation and inspection 
SNF-3896, Rev. 0

\section{APPENDIX A}

FUEL RETRIEVAL CLEANING CRITERIA 
SNF-3896, Rev. 0

\section{FUEL RETRIEVAL CLEANING CRITERIA}

Functional Requirement of the Fuel Cleaning System:

The fuel cleaning system must produce fuel that, when loaded in MCO's, can be shown to conform with bounding particulate inventory limits for the MCO.

The current approach to achieve this functional requirement is based on process qualification. After initial startup testing, a finite number of fuel canisters will be processed through the fuel cleaning machine while the operating parameters are controlled within defined ranges. Each element will be inspected to determine if it passes cleaning criteria. The purpose of the following discussion is to describe the basis for cleaning criteria used during cleaning machine qualification testing and subsequent operation.

Particulate Inventory Calculation Assumptions:

The current particulate inventory estimates, described in Sloughter 1998, are based on the following general assumptions:

- Fuel elements described as "bad" are assumed to be placed in scrap baskets.

- Fuel cleaning is equivalent to element transport to the laboratory.

The as-loaded contribution of MCO particulate inventory estimates are dependent on whether the estimate is considered bounding, nominal, or low. Four factors are included in the as-loaded particulate estimate: cladding film, oxide film, adhering particulate, and canister particulate. A summary of each factor, in terms applicable to consideration of observed cleaning criteria, is provided in the table below.

Safety basis calculations for project systems do not take credit for removal of films from the fuel surfaces. Therefore, cleaning criteria used during operation of the cleaning machine will demonstrate that functional requirements have been met if canister particulate removal is consistent with the bounding analysis in Sloughter, 1998. 
SNF-3896, Rev. 0

Particulate Estimates for a MCO with One Scrap Basket ${ }^{1}$

(Based on Sloughter, 1998)

\begin{tabular}{|c|c|c|c|c|}
\hline \multirow{2}{*}{\multicolumn{2}{|c|}{ Factor }} & \multicolumn{3}{|c|}{ Description } \\
\hline & & Bounding & Nominal & Low \\
\hline \multicolumn{2}{|c|}{$\begin{array}{c}\text { Cladding Film } \\
\text { (Mass basis is } \\
3156 \mathrm{~cm}^{2} / \text { assembly, } \\
216 \text { fuel assemblies in fuel } \\
\text { baskets and } 39 \text { assemblies in } \\
\text { scrap basket) }\end{array}$} & $\begin{array}{l}12.5 \mathrm{mg} / \mathrm{cm}^{2} \text { of } \mathrm{Al}(\mathrm{OH})_{3} \\
\text { coats all surfaces of all } \\
\text { assemblies loaded in a } \\
\mathrm{MCO} \text {. This is based on a } \\
\text { statistical analysis of } \\
\mathrm{Al}(\mathrm{OH})_{3} \text { measurements. } \\
(1.5 \mathrm{~kg} \text { on scrap, } 8.5 \mathrm{~kg} \text { on } \\
\text { fuel) }\end{array}$ & $\begin{array}{l}12.5 \mathrm{mg} / \mathrm{cm}^{2} \text { of } \mathrm{Al}(\mathrm{OH})_{3} \\
\text { coats all surfaces of } 25 \% \text { of } \\
\text { the assemblies loaded in a } \\
\mathrm{MCO} .0 .6 \mathrm{mg} / \mathrm{cm}^{2} \text { grayish } \\
\text { film coats all surfaces of } \\
75 \% \text { of the assemblies } \\
\text { loaded in a MCO. } \\
(0.4 \mathrm{~kg} \text { on scrap, } 2.4 \mathrm{~kg} \text { on } \\
\text { fuel })\end{array}$ & $\begin{array}{l}0.6 \mathrm{mg} / \mathrm{cm}^{2} \text { grayish film } \\
\text { coats all surfaces of all } \\
\text { assemblies loaded in a } \\
\text { MCO. } \\
(0.07 \mathrm{~kg} \text { on scrap, } 0.38 \mathrm{~kg} \\
\text { on fuel })\end{array}$ \\
\hline \multirow{2}{*}{$\begin{array}{l}\text { Oxide film } \\
\text { (4 fuel and } \\
\text { l scrap basket) }\end{array}$} & Scrap & $\begin{array}{l}10 \mathrm{~m} \text { thick oxide film on } \\
45,000 \mathrm{~cm}^{2} \text { of uranium } \\
\text { surface in the scrap pieces. } \\
(0.5 \mathrm{~kg})\end{array}$ & $\begin{array}{l}3 \mathrm{~m} \text { thick oxide film on } \\
17,000 \mathrm{~cm}^{2} \text { of uranium } \\
\text { surface in the scrap pieces. } \\
(0.05 \mathrm{~kg})\end{array}$ & $\begin{array}{l}3 \mathrm{~m} \text { thick oxide film on } \\
10,000 \mathrm{~cm}^{2} \text { of uranium } \\
\text { surface in the scrap pieces. } \\
(0.03 \mathrm{~kg})\end{array}$ \\
\hline & Fuel & $\begin{array}{l}10 \mathrm{~m} \text { thick oxide film on } \\
7,900 \mathrm{~cm}^{2} \text { of uranium } \\
\text { surface. } \\
(0.3 \mathrm{~kg})\end{array}$ & $\begin{array}{l}3 \mathrm{~m} \text { thick oxide film on } \\
425 \mathrm{~cm}^{2} \text { of uranium surface. } \\
(0.01 \mathrm{~kg})\end{array}$ & $\begin{array}{l}3 \mathrm{~m} \text { thick oxide film on } \\
160 \mathrm{~cm}^{2} \text { of uranium surface. } \\
(0.002 \mathrm{~kg})\end{array}$ \\
\hline \multirow{2}{*}{$\begin{array}{c}\text { Adhering } \\
\text { Particulate } \\
\text { (Mass basis is } \\
216 \text { fuel } \\
\text { assemblies in } \\
\text { fuel baskets and } \\
39 \text { assemblies in } \\
\text { scrap basket) }\end{array}$} & Scrap & $\begin{array}{l}\text { Adhering particulate, } \text { in } \\
\text { addition to coatings, at } \\
200 \mathrm{~g} / \text { assembly. } \\
(7.8 \mathrm{~kg})\end{array}$ & $\begin{array}{l}\text { Adhering particulate, in } \\
\text { addition to coatings, at } \\
20 \mathrm{~g} / \text { assembly. } \\
(0.8 \mathrm{~kg})\end{array}$ & $\begin{array}{l}\text { Adhering particulate, in } \\
\text { addition to coatings, at } \\
6 \mathrm{~g} / \text { assembly. } \\
(0.22 \mathrm{~kg})\end{array}$ \\
\hline & Fuel & $\begin{array}{l}\text { Adhering particulate, in } \\
\text { addition to coatings, at } \\
20 \mathrm{~g} / \text { assembly. } \\
(4.3 \mathrm{~kg})\end{array}$ & $\begin{array}{l}\text { Adhering particulate, in } \\
\text { addition to coatings, at } \\
7.6 \text { g/assembly. } \\
(1.64 \mathrm{~kg})\end{array}$ & $\begin{array}{l}\text { Adhering particulate, in } \\
\text { addition to coatings, at } \\
1.3 \mathrm{~g} / \mathrm{assembly} \text {. } \\
(0.28 \mathrm{~kg})\end{array}$ \\
\hline \multirow[b]{2}{*}{$\begin{array}{l}\text { Cansiter } \\
\text { Particulate } \\
\text { (Mass basis is } \\
216 \text { fuel } \\
\text { assemblies in } \\
\text { fuel baskets) }\end{array}$} & Scrap & \multicolumn{3}{|c|}{$\begin{array}{l}\text { No canister particulate allocated to scrap. Any particulate contribution from partially intact } \\
\text { assemblies is off set by a reduction in the adhering particulate estimate for scrap. }\end{array}$} \\
\hline & Fuel & $\begin{array}{l}\text { Each assembly contains less } \\
\text { than } 1.3 \mathrm{~cm}^{3} \text { residual } \\
\text { canister sludge and } 99 \% \\
\text { confidence that no more } \\
\text { than } 15 \% \text { of canisters } \\
\text { contain an assembly that } \\
\text { retains more than } 1.3 \mathrm{~cm}^{3} . \\
(1.3 \mathrm{~kg})\end{array}$ & $\begin{array}{l}\text { Same as bounding without } \\
\text { assuming each assembly } \\
\text { contains the detection limit } \\
\text { quantity of canister } \\
\text { particulate. } \\
(0.52 \mathrm{~kg})\end{array}$ & $\begin{array}{l}\text { No canister particulate } \\
\text { deposits. } \\
(0 \mathrm{~kg})\end{array}$ \\
\hline \multicolumn{2}{|c|}{ Total as-loaded particulate } & $24.2 \mathrm{~kg}$ & $5.8 \mathrm{~kg}$ & $1.0 \mathrm{~kg}$ \\
\hline
\end{tabular}

Notes:

1 - Particulate estimates vary with the number of scrap baskets in a MCO.

Criteria and Basis: 
The cleaning criteria is based on demonstrating that the cleaning operation has successfully removed canister particulate from the assembly flow channels. The cleaning criteria is based on defining the quantity of sludge observed in flow channels after cleaning that cause an assembly to be considered inadequately cleaned. The definition of an assembly that fails the cleaning criteria is as follows:

An assembly fails the cleaning criteria if, when removing the inner element from the outer element, a quantity of corrosion product (sludge) is observed to fall out of the assembly to form the equivalent of a circular pile approximately 1 -inch in diameter (size of a quarter).

Note that this criteria is actually applied only to elements that are being separated during process validation startup testing and periodic assembly sampling that is performed to confirm operations are under control.

The basis for the cleaning criteria is, in some respects, a qualitatively selected value. However, once selected, the process validation testing must show that the particulate inventory of a MCO is bounded by the inventory assumed for safety analyses. Therefore, the criteria basis is the allocation for sludge in plugged flow channels that is included in Sloughter, et al. (1998).

The fuel cleaning validation test is currently analyzed assuming a pass/fail criteria for a canister, while cleaning is evaluated based on observation of individual assemblies and the bounding particulate inventory estimate that cleaning must support is evaluated on a MCO basis. Therefore, a method was developed for translating the cleaning criteria from a canister, to assembly and/or MCO basis.

The cleaning criteria on a canister basis makes use of the assembly cleaning criteria as follows, based on a pre-defined number of canisters forming a canister batch in the process validation test.

- If one assembly in a canister fails the assembly cleaning criteria, then the canister passes the canister cleaning criteria and there can be no more than one more assembly in the canister batch that fails the assembly cleaning criteria.

- If two assemblies in a canister fail the assembly cleaning criteria, then the canister passes the canister cleaning criteria and no more assemblies in the canister batch can fail the assembly cleaning criteria.

- If three assemblies in an batch of the process validation test fail the assembly cleaning criteria, then the batch fails the process validation test.

Passing the process validation test with a test batch size that provides $99 \%$ confidence that no more than $15 \%$ of the canisters will fail the cleaning criteria on a canister basis, combined with the cleaning criteria described above, produces a process performance test consistent with the residual canister particulate analysis in Sloughter, 1998. 
SNF-3896, Rev. 0

References:

Sloughter, J. P., et al., 1998, Estimates of Particulate Mass in Multi-Canister Overpacks, HNF-1527, Rev 2, Numatec Hanford Corp., Richland, Wa. 
SNF-3896, Rev. 0

APPENDIX B

SAMPLE SIZE CALCULATIONS 


\section{Sample Size}

A. Determine the number of canisters which need to be sampled (cleaned) and inspected such that inferences about the entire canister population can be made.

1. State the null hypothesis [the population fraction defective (not clean) is $\leq \mathrm{p}_{0}$ ].

2. State the alternate hypothesis [the population fraction defective (not clean) is $>\mathrm{p}_{1}$.

3. Identify the Type I error probability $(\alpha)$. A Type I error is rejecting the null hypothesis when it is really true; i.e., stating that fuel is not clean when it really is clean.

4. Identify the Type II error probability ( $\beta$ ). A Type II error is not rejecting the null hypothesis when it is really true; i.e., stating that the fuel is clean when it is not clean.

5. Calculate the number of canisters (n) to be sampled using equation 1 which is based on the hypergeometric distribution. This formula (Bowen, 1988) is for the case where the null hypothesis is "no defective items in the population"; i.e., $p_{0}=$ 0 . Thus, the Type I error probability is zero. This special case simplifies the computations needed to calculate the sample size. The inferences to the canister population are based on the absence of defects found in the sampling of the $n$ canisters.

$$
n=0.5\left(1-\beta^{1 / D_{A}}\right)\left(2 N-D_{A}+1\right) \quad(\text { eqn. 1) }
$$

where

$\mathrm{n}=$ the number of items to be sampled (rounded up to the nearest integer)

$\beta=$ the probability of a Type II error (probability of stating an item is "clean" when it is "not clean")

$D_{A}=$ the number of defects allowed with probability $\beta$ and

$\mathrm{N}=$ the total number of items in the population 
SNF-3896, Rev. 0

Table 1 provides the sample size calculations for the $\mathrm{KW}$ canister population varying both the Type II error probability and the percent defective allowed with probability $\beta$.

Table 2 provides the sample size calculations for the KE canister population varying both the Type II error probability and the percent defective allowed with probability $\beta$.

\section{EXAMPLES}

If $\beta=0.05$ and $p_{1}=0.05$ then $58 \mathrm{KW}$ canisters are cleaned and inspected $\left(p_{1}\right.$ of 0.05 means that $5 \%$ of the $\mathrm{KW}$ canisters could be sent to the $\mathrm{MCO}$ as not cleaned).

If $\beta=0.05$ and $p_{1}=0.01$ then $287 \mathrm{KW}$ canisters are cleaned and inspected. 
SNF-3896, Rev. 0

Table 1. KW Canister Sample Size Calculations.

\begin{tabular}{|c|c|c|c|c|}
\hline $\mathrm{N}$ & $\beta$ & $\%$ Non-Defective & $\%$ Defective & $\mathbf{n}$ \\
\hline 3820 & 0.2 & 0.800 & 0.200 & 8 \\
\hline 3820 & 0.2 & 0.850 & 0.150 & 10 \\
\hline 3820 & 0.2 & 0.900 & 0.100 & 16 \\
\hline 3820 & 0.2 & 0.950 & 0.050 & 32 \\
\hline 3820 & 0.2 & 0.960 & 0.040 & 40 \\
\hline 3820 & 0.2 & 0.970 & 0.030 & 53 \\
\hline 3820 & 0.2 & 0.980 & 0.020 & 79 \\
\hline 3820 & 0.2 & 0.990 & 0.010 & 157 \\
\hline 3820 & 0.2 & 0.995 & 0.005 & 308 \\
\hline 3820 & 0.1 & 0.800 & 0.200 & 11 \\
\hline 3820 & 0.1 & 0.850 & 0.150 & 15 \\
\hline 3820 & 0.1 & 0.900 & 0.100 & 22 \\
\hline 3820 & 0.1 & 0.950 & 0.050 & 45 \\
\hline 3820 & 0.1 & 0.960 & 0.040 & 56 \\
\hline 3820 & 0.1 & 0.970 & 0.030 & 75 \\
\hline 3820 & 0.1 & 0.980 & 0.020 & 113 \\
\hline 3820 & 0.1 & 0.990 & 0.010 & 223 \\
\hline 3820 & 0.1 & 0.995 & 0.005 & 433 \\
\hline 3820 & 0.05 & 0.800 & 0.200 & 14 \\
\hline 3820 & 0.05 & 0.850 & 0.150 & 19 \\
\hline 3820 & 0.05 & 0.900 & 0.100 & 29 \\
\hline 3820 & 0.05 & 0.950 & 0.050 & 58 \\
\hline 3820 & 0.05 & 0.960 & 0.040 & 73 \\
\hline 3820 & 0.05 & 0.970 & 0.030 & 98 \\
\hline 3820 & 0.05 & 0.980 & 0.020 & 146 \\
\hline 3820 & 0.05 & 0.990 & 0.010 & 287 \\
\hline 3820 & 0.05 & 0.995 & 0.005 & 554 \\
\hline 3820 & 0.01 & 0.800 & 0.200 & 21 \\
\hline 3820 & 0.01 & 0.850 & 0.150 & 29 \\
\hline 3820 & 0.01 & 0.900 & 0.100 & 44 \\
\hline 3820 & 0.01 & 0.950 & 0.050 & 89 \\
\hline 3820 & 0.01 & 0.960 & 0.040 & 112 \\
\hline 3820 & 0.01 & 0.970 & 0.030 & 149 \\
\hline 3820 & 0.01 & 0.980 & 0.020 & 222 \\
\hline 3820 & 0.01 & 0.990 & 0.010 & 432 \\
\hline 3820 & 0.01 & 0.995 & 0.005 & 817 \\
\hline
\end{tabular}


SNF-3896, Rev. 0

Table 2. KE Canister Sample Size Calculations.

\begin{tabular}{|c|c|c|c|c|}
\hline $\mathbf{N}$ & $\beta$ & $\%$ Non-Defective & $\%$ Defective & $n$ \\
\hline 3670 & 0.2 & 0.800 & 0.200 & 8 \\
\hline 3670 & 0.2 & 0.850 & 0.150 & 10 \\
\hline 3670 & 0.2 & 0.900 & 0.100 & 16 \\
\hline 3670 & 0.2 & 0.950 & 0.050 & 32 \\
\hline 3670 & 0.2 & 0.960 & 0.040 & 40 \\
\hline 3670 & 0.2 & 0.970 & 0.030 & 53 \\
\hline 3670 & 0.2 & 0.980 & 0.020 & 79 \\
\hline 3670 & 0.2 & 0.990 & 0.010 & 157 \\
\hline 3670 & 0.2 & 0.995 & 0.005 & 308 \\
\hline 3670 & 0.1 & 0.800 & 0.200 & 11 \\
\hline 3670 & 0.1 & 0.850 & 0.150 & 15 \\
\hline 3670 & 0.1 & 0.900 & 0.100 & 22 \\
\hline 3670 & 0.1 & 0.950 & 0.050 & 45 \\
\hline 3670 & 0.1 & 0.960 & 0.040 & 56 \\
\hline 3670 & 0.1 & 0.970 & 0.030 & 75 \\
\hline 3670 & 0.1 & 0.980 & 0.020 & 113 \\
\hline 3670 & 0.1 & 0.990 & 0.010 & 223 \\
\hline 3670 & 0.1 & 0.995 & 0.005 & 432 \\
\hline 3670 & 0.05 & 0.800 & 0.200 & 14 \\
\hline 3670 & 0.05 & 0.850 & 0.150 & 19 \\
\hline 3670 & 0.05 & 0.900 & 0.100 & 29 \\
\hline 3670 & 0.05 & 0.950 & 0.050 & 58 \\
\hline 3670 & 0.05 & 0.960 & 0.040 & 73 \\
\hline 3670 & 0.05 & 0.970 & 0.030 & 98 \\
\hline 3670 & 0.05 & 0.980 & 0.020 & 146 \\
\hline 3670 & 0.05 & 0.990 & 0.010 & 287 \\
\hline 3670 & 0.05 & 0.995 & 0.005 & 552 \\
\hline 3670 & 0.01 & 0.800 & 0.200 & 21 \\
\hline 3670 & 0.01 & 0.850 & 0.150 & 29 \\
\hline 3670 & 0.01 & 0.900 & 0.100 & 44 \\
\hline 3670 & 0.01 & 0.950 & 0.050 & 89 \\
\hline 3670 & 0.01 & 0.960 & 0.040 & 112 \\
\hline 3670 & 0.01 & 0.970 & 0.030 & 149 \\
\hline 3670 & 0.01 & 0.980 & 0.020 & 221 \\
\hline 3670 & 0.01 & 0.990 & 0.010 & 431 \\
\hline 3670 & 0.01 & 0.995 & 0.005 & 813 \\
\hline
\end{tabular}


SNF-3896, Rev. 0

APPENDIX C

STATISTICAL PROCESS CONTROL 


\section{CONTROL CHARTS}

A control chart (Ford, 1984) is a basis of interpreting the data generated from a process for statistical control. It is a simple and effective tool to achieve statistical control.

A control chart consists of a center line (mean percent defective), two control limits (mean $\pm 3 * \sigma$ ), and two warning limits (mean $\pm 2 * \sigma$ ). The process variability is represented by $\sigma$. Excessive sludge in the MCOs is of concern to the SNF cleaning process. Therefore, only the upper warning and control limits are of interest to the SNF process.

The control chart used to monitor the SNF cleaning process is the $\mathrm{p}$-Chart. The $\mathrm{p}$-Chart measures the proportion of SNF fuel that do not pass the cleaning criteria.

After the 29 randomly selected canisters have been cleaned and inspected (validation phase), a p-Chart will be generated in order to (1) monitor the process assuring that the process parameters remain effective in controlling the cleanliness of the SNF and (2) make inferences regarding the canister population after being processed through the cleaning system.

\section{Generating the p-Chart}

1. For each canister, determine the percent defective using equation 2 where $p$ is the fraction defective for the canister, $d$ is the number of failed assemblies from the canister, and $\mathrm{N}$ is the total number of assemblies for the canister. (A control chart based on individual elements can also be generated.)

$$
\mathrm{p}=\frac{\mathrm{d}}{\mathrm{N}} \quad \text { (eqn. 2) }
$$

2. Graph the percent defective observed for each canister versus the canister number (order in which the canisters were processed); i.e. produce a p-chart.

3. Calculate the overall mean percent defective using equation 3 .

$$
\begin{gathered}
\left.\bar{p}=\frac{d_{1}+d_{2}+\ldots+d_{k}}{N_{1}+N_{2}+\ldots+N_{k}} \quad \text { (eqn. } 3\right) \\
\text { where } d_{i}=\text { number of defectives per batch } \\
N_{i}=\text { number of pieces per batch }
\end{gathered}
$$

4. Calculate the upper control limit for the proportion defective (not clean) using equation 4. 


$$
\mathrm{UCL}_{\mathrm{p}}=\overline{\mathrm{p}}+\frac{3 \sqrt{\overline{\mathrm{p}}(1-\overline{\mathrm{p}})}}{\sqrt{\overline{\mathrm{N}}}} \quad \text { (eqn. 4) }
$$

5. Calculate the upper warning limit for the proportion defective (not clean) using

$$
\mathrm{UWL}_{p}=\overline{\mathrm{p}}+\frac{2 \sqrt{\overline{\mathrm{p}}(1-\overline{\mathrm{p}})}}{\sqrt{\overline{\mathrm{N}}}} \quad \text { (eqn. 5) }
$$

equation 5.

6. Plot the warning and control limits on the p-chart.

\section{Interpreting the Control Chart}

The objective of control chart analysis is to identify any evidence that the process variability or the process average are not operating at a constant level and to take appropriate action. Some rules for interpreting a control chart are as follows.

1. A point beyond the control limits is generally a sign that (1) the process is "out of control", (2) the control limits are in error, (3) the observation (percent defective for a canister) could be in error, or (4) the measurement system changed (e.g., different gauge or new operator).

2. Two of three consecutive observations outside the warning limits is an indication that the process is "out of control".

3. At least eight consecutive points on one side of the mean is an indication of a shift in the process mean.

4. At least eight consecutive points increasing or decreasing is an indication of a trend in the process.

If the p-Chart indicates that the cleaning process is "Out of Statistical Control", then examination of the process needs to take place. Some steps are as follows.

1. Check the data

2. Check the process parameters to see if they are within administratively tolerance intervals.

3. Check the historical data for the canister fuel. Do the eight consecutive observations have the same fuel parameters? Did the fuel damage level keep increasing for the eight consecutive observations? Was the fuel in the canister unique? 
SNF-3896, Rev. 0

4. If nothing unusual is found, analyze (clean, separate the fuel, and inspect) two additional canisters (control samples) to see if the process is still "out of control".

5. If steps 1 through 3 show nothing unusual and the additional control samples are within the control limits, the FRS cleaning process is continued.

6. If steps 1 through 3 show nothing unusual and the additional control samples are still outside control limits, an SPC failure is declared and the FRS cleaning process is stopped and evaluated to ascertain why the process went "out of control". All batches since the last monitored control sample would need to be recycled through the cleaning process, fuel separated, and inspected.

\section{P-Chart Examples}

Table 3 contains data that illustrate possible outcomes from the validation phase. Table 3 assumes that each canister contained 14 assemblies and that only 2 assemblies from the validation batch failed the cleaning criteria. The two scenarios are illustrated in Figures 1 and 2 .

Both control charts indicate that NO assemblies from the canisters selected for inspection during the production phase can fail the cleaning criteria (since $1 / 14=0.071$ is greater than the $\mathrm{UCL}=$ 0.061). Therefore, generation of a $\mathrm{p}$-chart will not be required for the production phase. 
SNF-3896, Rev. 0

Table 3. Hypothetical Validation Phase Data

\begin{tabular}{|c|c|c|c|c|c|}
\hline Canister & Assemblies & $\begin{array}{c}\text { Option 1a } \\
\text { Failed Assemblies }\end{array}$ & $\begin{array}{c}\text { Option la } \\
\text { Proportion Failed }\end{array}$ & $\begin{array}{c}\text { Option lb } \\
\text { Failed Assemblies }\end{array}$ & $\begin{array}{c}\text { Option } 1 \mathrm{~b} \\
\text { Proportion Failed }\end{array}$ \\
\hline 1 & 14 & 0 & 0.000 & 0 & 0.000 \\
\hline 2 & 14 & 0 & 0.000 & 0 & 0.000 \\
\hline 3 & 14 & 0 & 0.000 & 0 & 0.000 \\
\hline 4 & 14 & 1 & 0.071 & 0 & 0.000 \\
\hline 5 & 14 & 0 & 0.000 & 0 & 0.000 \\
\hline 6 & 14 & 0 & 0.000 & 0 & 0.000 \\
\hline 7 & 14 & 0 & 0.000 & 0 & 0.000 \\
\hline 8 & 14 & 0 & 0.000 & 0 & 0.000 \\
\hline 9 & 14 & 0 & 0.000 & 0 & 0.000 \\
\hline 10 & 14 & 0 & 0.000 & 0 & 0.000 \\
\hline 11 & 14 & 0 & 0.000 & 0 & 0.000 \\
\hline 12 & 14 & 0 & 0.000 & 2 & 0.143 \\
\hline 13 & 14 & 0 & 0.000 & 0 & 0.000 \\
\hline 14 & 14 & 0 & 0.000 & 0 & 0.000 \\
\hline 15 & 14 & 0 & 0.000 & 0 & 0.000 \\
\hline 16 & 14 & 0 & 0.000 & 0 & 0.000 \\
\hline 17 & 14 & 1 & 0.071 & 0 & 0.000 \\
\hline 18 & 14 & 0 & 0.000 & 0 & 0.000 \\
\hline 19 & 14 & 0 & 0.000 & 0 & 0.000 \\
\hline 20 & 14 & 0 & 0.000 & 0 & 0.000 \\
\hline 21 & 14 & 0 & 0.000 & 0 & 0.000 \\
\hline 22 & 14 & 0 & 0.000 & 0 & 0.000 \\
\hline 23 & 14 & 0 & 0.000 & 0 & 0.000 \\
\hline 24 & 14 & 0 & 0.000 & 0 & 0.000 \\
\hline 25 & 14 & 0 & 0.000 & 0 & 0.000 \\
\hline 26 & 14 & 0 & 0.000 & 0 & 0.000 \\
\hline 27 & 14 & 0 & 0.000 & 0 & 0.000 \\
\hline 28 & 14 & 0 & 0.000 & 0 & 0.000 \\
\hline 29 & 14 & 0 & 0.000 & 0 & 0.000 \\
\hline
\end{tabular}


Option 1a: 2 Assembly Failures

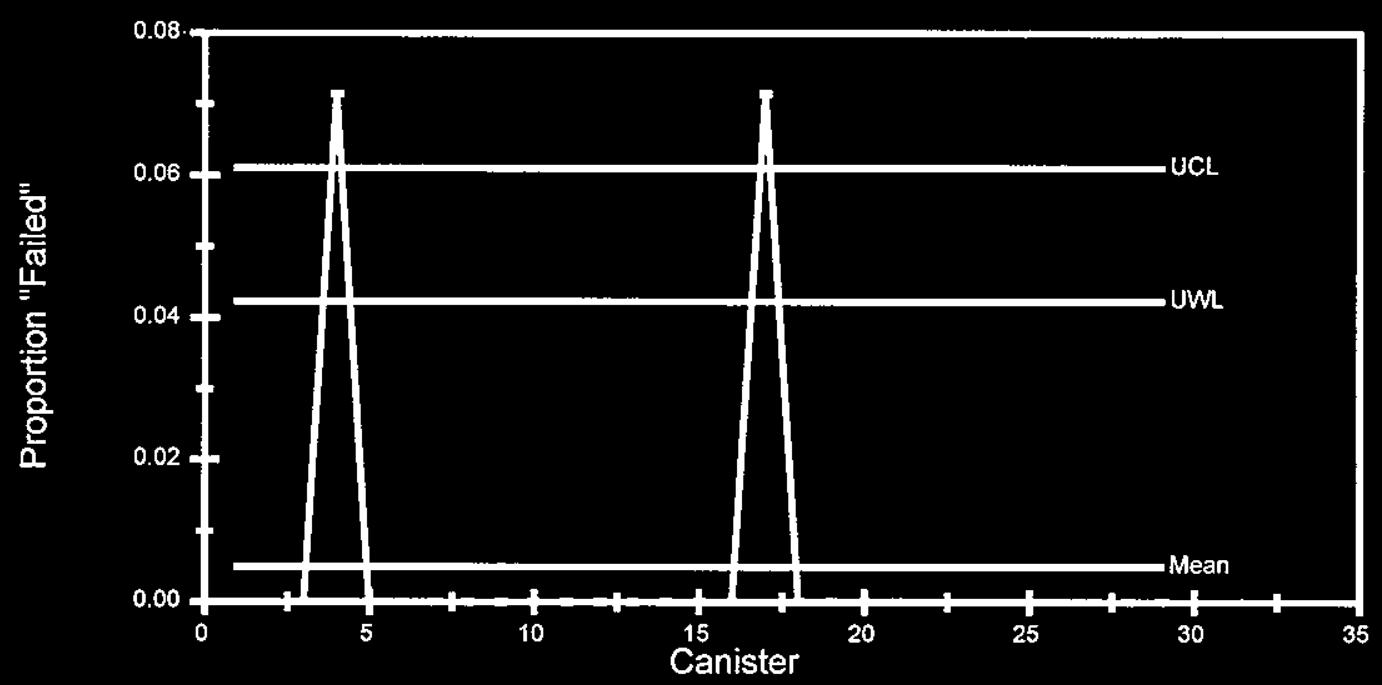

Option 1b: 2 Assembly Failures

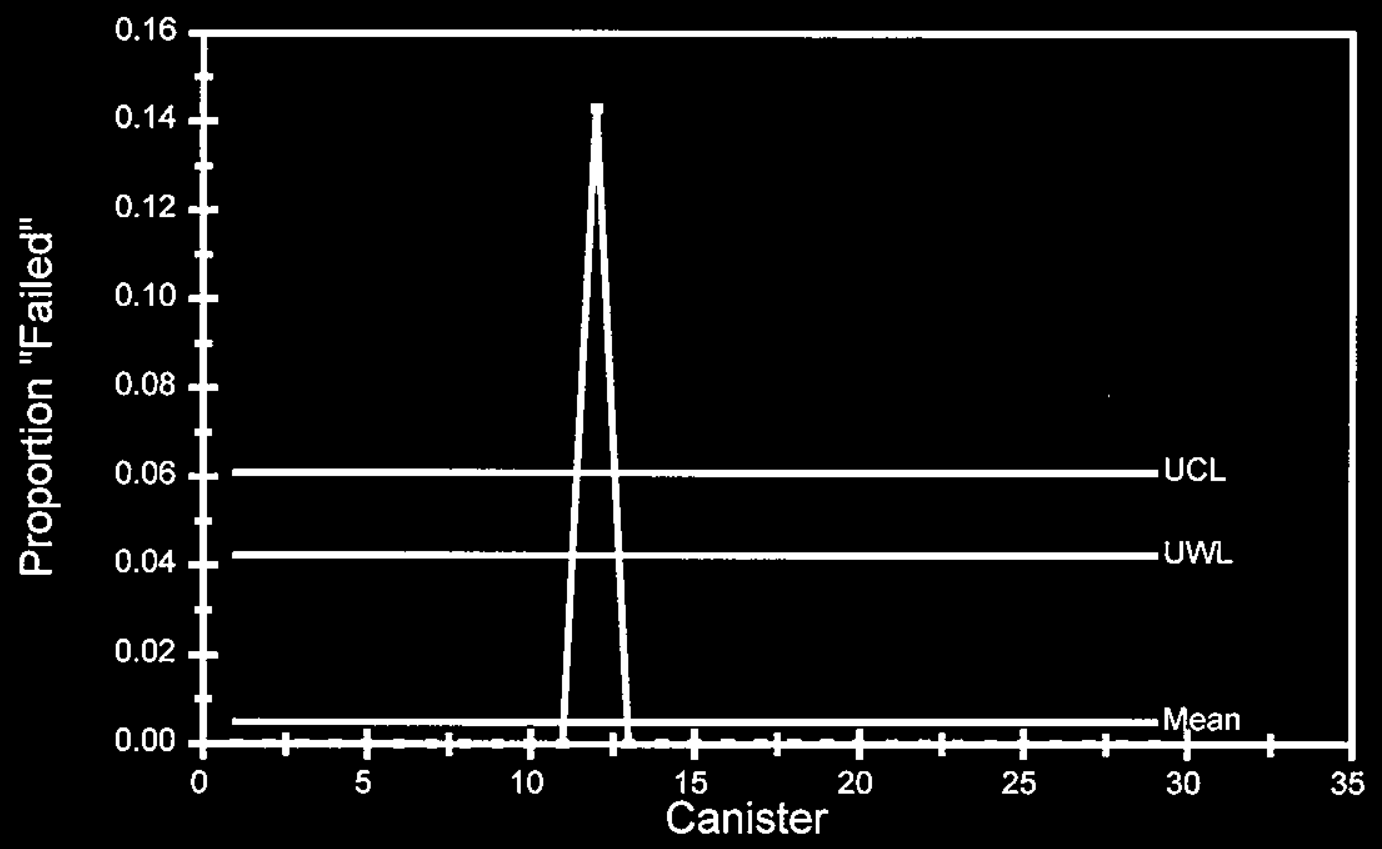




\section{DISTRIBUTION SHEET}

To

Distribution

Project Title/Work Order

SNF Fuel Retrieval Subproject / A.7
From

Fuel Retrieval Subproject
Page 1 of 1

Date 6/17/99

EDT No. 626040

ECN No.

Name

S.P. Anderson

L.I. Blehm

J.F. Bowser

J.R. Cassidy

J.I. Dieh1

V.R. Enderlin

J.R. Frederickson

B.D. Groth

J.M. Henderson

D.R. Jackson

R.A. Kaye

M.J. Langevin

J.D. Mathews

D.T. Mildon

K.R. Morris

P.A. Mulkey

A.L. Pajunen

S.H. Peck

T.J. Ruane

L.S. Schroeder

T.L. Welsh

$\mathrm{K}$ Basin Project Files

FRS Working Files

\begin{tabular}{c|c|c|c|c} 
MSIN & $\begin{array}{c}\text { Text } \\
\text { With All } \\
\text { Attach. }\end{array}$ & Text Only & $\begin{array}{c}\text { Attach./ } \\
\text { Appendix } \\
\text { Only }\end{array}$ & $\begin{array}{c}\text { EDT/ECN } \\
\text { Only }\end{array}$ \\
\hline
\end{tabular}

